\title{
First regional training course for dissemination officers of the English-speaking National Societies of east and southern Africa and the Indian Ocean
}

(Harare, 13-22 November 1989)

The first regional training course on international humanitarian law and the Fundamental Principles of the Movement for dissemination officers of the English-speaking National Societies of east and southern Africa and the Indian Ocean, organized by the International Committee of the Red Cross, the ICRC regional delegation in Harare, the regional delegation of the League of Red Cross and Red Crescent Societies and the Zimbabwe Red Cross, was held in Harare from 13 to 22 November 1989.

The course was attended by 32 National Society representatives from the following 15 countries: Botswana, Ethiopia, Kenya, Lesotho, Malawi, Mauritius, Namibia, the Seychelles, Somalia, South Africa, Sudan, Tanzania, Uganda, Zambia and Zimbabwe. Participants included not only information and dissemination officers, but also the President of the Seychelles Red Cross and the Deputy Secretary General of the Kenya Red Cross.

The programme called for the active participation of all the officers present, and each topic (e.g., history and structure of the Movement, the Fundamental Red Cross and Red Crescent Principles, international humanitarian law, the red cross and red crescent emblems, operational activities, disaster preparedness, development and dissemination) was introduced by a practical exercise carried out by the participants divided into working groups. The results were then reviewed in a general discussion, and the session ended with a summary highlighting the main points.

Speakers included Mr. Herbert Hyange, a Tanzanian jurist from Dar es Salaam Law Faculty, Mr. Henry Wahinya, the information officer of the Kenya Red Cross, the ICRC and League regional delegates in Harare and Mr. Leonard Isler, head of the Africa Section of the ICRC's Co-operation and Dissemination Division. 
The course made extensive use of video exercises, and the method proved extremely successful: all the participants expressed the wish to meet again in a few years' time for a refresher course, which would provide them with an opportunity to discuss the experience acquired in the meantime.

\section{L.I.}

